\title{
Object Model of Technical Solutions for Designing a Locomotive Train
}

\author{
Dmitry Antipin ${ }^{1 *}$, Vladimir Vorobiev ${ }^{1}$, and Denis Bondarenko ${ }^{1}$ \\ ${ }^{1}$ EDP Department of "Rolling stock of railways" FSBEI of HE "Bryansk State Technical \\ University"241035 Bryansk, Russia
}

\begin{abstract}
The task of creating a method for constructing components and parts of a locomotive drive, allowing not only to simulate the physical properties of the latter but also to form and automate the recognition of technical solutions, is considered. A model of a traction drive, which is a system of sets of descriptions of real objects of the set which makes it possible to create mathematical models of the structure in the form of a set of related elements included in the libraries of well- known solutions, is proposed. In contrast to previously known methods based on the procedure of creating new solutions under which a prototype of the structure is made and then improved on the basis of an empirical analysis of its development (while the design task is to create new structures). In the proposed method the basis for the construction of the technical system objective model is the classification of technical systems. Solutions to eleminate jamming of the sleeves of the axes with the transverse movement of the engine are proposed. A patent for the invention and two patents for the utility models are obtained.
\end{abstract}

\section{Introduction}

At newly designed locomotives there are failures of various units of the wheel-motor unit, as described in [1-3]. Attempts to improve reliability due to the integration of tractive motor (TM) and axial gearbox (electric 2ES10 locomotive) lead to low drive manufacturability, increased requirements for manufacturing accuracy, and more complicated repairs. The reason is that the well-known CAD systems allow you to simulate the physical properties of parts and assemblies, but the recognition of technical solutions remains subjective, and this affects the efficiency of the choice of design options. A number of design methods, based on models of the design process, according to the classification $[4,5]$, related to algorithmic models are known. But they are empirical in nature, which does not provide unambiguous criteria for choosing the best algorithm for a set of possible algorithms for finding a technical solution. In this case, the algorithms were calculated on the use of them by a man, without the possibility of use in CAD. The proposed article is an attempt to solve this problem.

\footnotetext{
*Corresponding author: adya2435@gmail.com
} 


\section{Solution technique}

According to the concept outlined in [6-8], the traction drive system can be represented by the five:

$$
C=\left(\varphi, R, A^{(s)}, A^{(R s)}, A^{(s R)}\right)
$$

where the set $\varphi=\left\{S_{1}, \ldots S_{p}\right\}$ is the composition of the system, where $S_{1}, \ldots S_{p}$ are the internal elements of $C$, the set of $R=\left\{R_{l}, \ldots R_{q}\right\}$ is the environment (supersystem), and $R_{l}, \ldots R_{q}$ are the external elements of $C$, the set $A$ (s) is all $n$-ary relations on the elements (the internal structure of system $C$ ), and the sets $A(s R)$ and $A(R s)$ are all $n$-ary relations between the elements of the sets $\varphi$ and $R$ (the structure of the interaction of the systems with the environment).

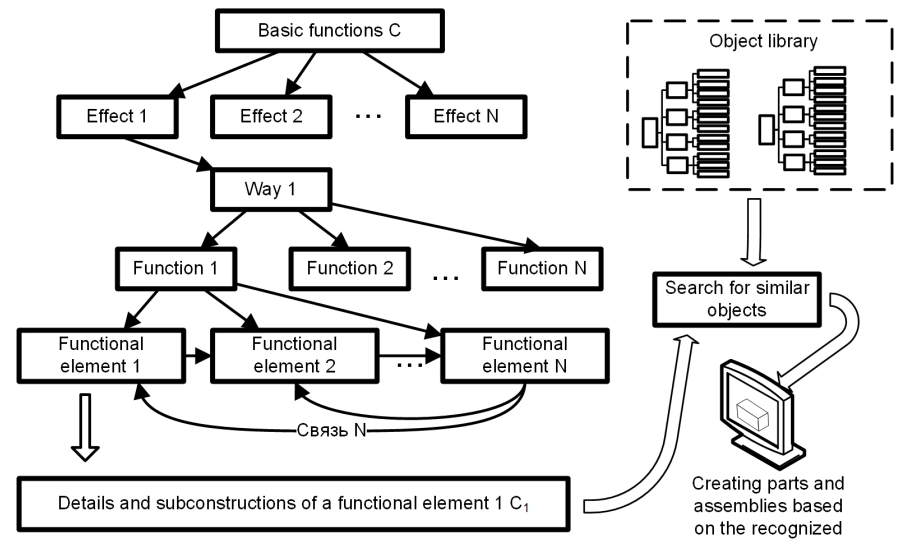

Fig. 1. Scheme of the generalized object model of traction drive design.

A traction drive model is a system of descriptions of real objects of a set, while the $\alpha: \phi^{\prime} \rightarrow \phi$ mapping is considered to be a homomorphic mapping of the set of real objects $\phi^{\prime}=\left\{S_{1}^{\prime}, \ldots S_{p}^{\prime}\right\}$ to the set of their descriptions. $\varphi=\left\{S_{1} \ldots S_{p}\right\}$, if $\varphi$ has the same composition as the set $\varphi^{\prime}$. The $C^{\prime}=C\left(\phi^{\prime}, R^{\prime}, A^{\left(s^{\prime}\right)}, A^{\left(R^{\prime} s^{\prime}\right)}, A^{\left(s^{\prime} R^{\prime}\right)}\right)$ system mapping to the $C=C\left(\phi, R, A^{(S)}, A^{(R S)}, A^{(S R)}\right)$ system is considered specified if the five $\alpha_{1}: \phi^{\prime} \rightarrow \phi ; \alpha_{2}: R^{\prime} \rightarrow R$; $\alpha_{3}: A^{\left(S^{\prime}\right)} \rightarrow A^{(S)} ; \alpha_{4}: A^{\left(R^{\prime} S^{\prime}\right)} \rightarrow A^{(R S)} ; \alpha_{5}: A^{\left(S^{\prime} R^{\prime}\right)} \rightarrow A^{(S R)}$. 


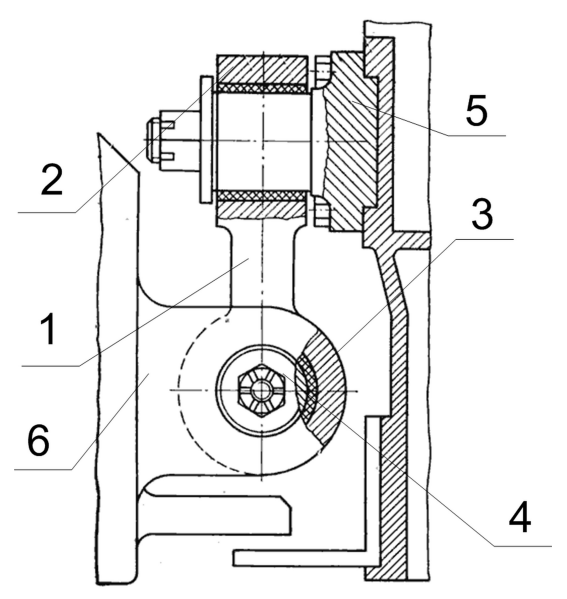

Fig. 2. Breaking up into substructures of the suspension of an electric motor: 1 - "Traction"; 2 "Upper hinge"; 3 - "Lower hinge"; 4 - "Axis"; 5 - "Bracket on the trolley frame"; 6 - "TM Bracket"

This makes it possible to create mathematical models of structures in the form of a set of related elements belonging to the library of known solutions. For example, the suspension of the HS4000 locomotive electric motor (Fig. 1) can be can be represented as a system from the "Traction", "Upper hinge" and "Lower hinge" structures, which are connected with the "Axis", "Bracket on the frame" carts and "Bracket TM" and with each other. The disadvantage of the method [9-14] is the procedure for creating new solutions, in which the prototype of the structure is located, and then improved on the basis of an empirical analysis of its development, while the main task of the design is the creation of new structures.

According to [9-11], the basis for constructing an object model of a technical system is the classification of technical systems. The authors proposed a classification of traction drives for rail rolling stock [12-14], and in [15] a method was proposed for creating such classifications based on the design process model proposed by the authors in [16]. Thus, an object model, that is, describing the structure of the objects that make up the system, their attributes, operations, interconnections with other objects, and reflecting the pragmatics of the system being developed [17], should reflect the algorithmic model of the design process as a basis for classification and increase the degree of automation design due to the standardization of elements and components. For this purpose, a generalized object model of a locomotive drive consists of two parts - a hierarchy of sets of descriptions of a drive with different degrees of schematization, and a library containing descriptions of typical objects described in the form of a hierarchical structure of functional interaction between elements (I-graph), with this, at the level of determining the functional elements of the drive, the search for similar objects in the library using the similarity matrix takes place (Fig. 2).

Table 1. Characteristics of TM suspension options.

\begin{tabular}{|c|c|c|c|c|c|c|c|}
\hline & $\begin{array}{c}\mathbf{R}_{1} \\
\text { Project }\end{array}$ & $\begin{array}{c}\mathbf{R}_{\mathbf{2}} \\
\text { HS4000 }\end{array}$ & $\begin{array}{c}\mathbf{R}_{\mathbf{3}} \\
\text { TEM10 } \\
\mathbf{3} \\
\end{array}$ & $\begin{array}{c}R_{4} \\
\text { VL80t }\end{array}$ & $\begin{array}{c}\text { R5 } \\
2 \text { ES5 }\end{array}$ & $\begin{array}{c}\mathbf{R}_{6} \\
\text { 2ES10 }\end{array}$ & $\begin{array}{c}\mathbf{R}_{7} \\
\text { 2TE25A }\end{array}$ \\
\hline $\mathrm{S}_{1}$ & $\begin{array}{l}\text { Whole } \\
\text { thrust }\end{array}$ & $\begin{array}{l}\text { Whole } \\
\text { thrust }\end{array}$ & $\begin{array}{l}\text { Whole } \\
\text { thrust }\end{array}$ & $\begin{array}{l}\text { Whole } \\
\text { thrust }\end{array}$ & $\begin{array}{l}\text { Whole } \\
\text { thrust }\end{array}$ & $\begin{array}{l}\text { Whole } \\
\text { thrust }\end{array}$ & - \\
\hline $\mathrm{S}_{2}$ & - & - & - & - & - & - & $\begin{array}{l}\text { Welded } \\
\text { thrust }\end{array}$ \\
\hline $\mathrm{S}_{3}$ & $\begin{array}{c}\text { Cylinder } \\
\text { hinge }\end{array}$ & $\begin{array}{c}\text { Cylinder } \\
\text { hinge }\end{array}$ & $\begin{array}{c}\text { Cylinder } \\
\text { hinge }\end{array}$ & $\begin{array}{c}\text { Cylinder } \\
\text { hinge }\end{array}$ & $\begin{array}{c}\text { Cylinder } \\
\text { hinge }\end{array}$ & - & - \\
\hline
\end{tabular}




\begin{tabular}{|c|c|c|c|c|c|c|c|}
\hline $\mathrm{S}_{4}$ & $\begin{array}{l}\text { Spherical } \\
\text { hinge }\end{array}$ & $\begin{array}{c}\text { Spherical. } \\
\text { hinge }\end{array}$ & - & - & - & $\begin{array}{c}\text { Spherical. } \\
\text { hinge }\end{array}$ & $\begin{array}{c}\text { Spherical } \\
\text { hinge }\end{array}$ \\
\hline $\mathrm{S}_{5}$ & - & - & - & $\begin{array}{c}\text { Flat } \\
\text { washers }\end{array}$ & $\begin{array}{c}\text { Flat } \\
\text { washers }\end{array}$ & - & - \\
\hline $\mathrm{S}_{6}$ & Guide & - & Guide & Guide & Guide & - & - \\
\hline $\mathrm{S}_{7}$ & - & - & - & - & - & Wedges & Wedges \\
\hline $\mathrm{S}_{8}$ & $\begin{array}{l}\text { Frame } \\
\text { bracket }\end{array}$ & $\begin{array}{l}\text { Frame } \\
\text { bracket }\end{array}$ & $\begin{array}{l}\text { Frame } \\
\text { bracket }\end{array}$ & $\begin{array}{l}\text { Frame } \\
\text { bracket }\end{array}$ & $\begin{array}{l}\text { Frame } \\
\text { bracket }\end{array}$ & $\begin{array}{l}\text { Frame } \\
\text { bracket }\end{array}$ & $\begin{array}{l}\text { Frame } \\
\text { bracket }\end{array}$ \\
\hline $\mathrm{S}_{9}$ & $\begin{array}{c}\text { Bracket. } \\
\text { TM }\end{array}$ & $\begin{array}{c}\text { Bracket. } \\
\text { TM }\end{array}$ & $\begin{array}{c}\text { Bracket. } \\
\text { TM }\end{array}$ & $\begin{array}{c}\text { Bracket } \\
\text { TM }\end{array}$ & $\begin{array}{c}\text { Bracket } \\
\text { TM }\end{array}$ & $\begin{array}{c}\text { Bracket } \\
\text { TM }\end{array}$ & $\begin{array}{c}\text { Bracket. } \\
\text { TM }\end{array}$ \\
\hline $\mathrm{S}_{10}$ & $\begin{array}{c}\text { Parallel } \\
\text { axes }\end{array}$ & - & $\begin{array}{c}\text { Parallel } \\
\text { axes }\end{array}$ & $\begin{array}{c}\text { Parallel } \\
\text { axes }\end{array}$ & $\begin{array}{c}\text { Parallel } \\
\text { axes }\end{array}$ & $\begin{array}{c}\text { Parallel } \\
\text { axes }\end{array}$ & $\begin{array}{c}\text { Parallel } \\
\text { axes }\end{array}$ \\
\hline$S_{11}$ & - & $\begin{array}{c}\text { Crossed } \\
\text { axes }\end{array}$ & - & - & - & - & - \\
\hline $\mathrm{S}_{12}$ & - & $\begin{array}{c}\text { Nut } \\
\text { on the axis }\end{array}$ & - & - & - & - & - \\
\hline
\end{tabular}

Let us take the measure of similarity in the form of a nonnegative real function

$$
C\left(R_{i} R_{j}\right)=\frac{2 m\left(R_{i} \cap R_{j}\right)}{m\left(R_{i}\right)+m\left(R_{j}\right)}
$$

where $m\left(R_{i} \cap R_{j}\right)$ - a number of common types in descriptions $R_{i}$ and $R_{j}, m\left(R_{i}\right)$ and $m\left(R_{j}\right)$ - a number of types in descriptions $R_{i}$ and $R_{j}$. Let $R_{l}$ be the description of the projected torsion shaft, $R_{2}-R_{7}-$ the prototype descriptions, $S_{1}-S_{12}$ - the attributes of the objects (Table 1), based on Table 1 we compile the lists of types (Table 2a). Let the sets $m\left(R_{i}\right), m\left(R_{j}\right)$ be the number of signs of the $i$-th and $j$-th variant in the species lists, the set is the number of signs that the $i$-th and $j$-th variants simultaneously have. Then the measure of the inclusion of the set of features of the $i$-th variant in the $j$-th is:

$$
W\left(R_{j} ; R_{i}\right)=\frac{m\left(R_{i} \cap R_{j}\right)}{m\left(R_{i}\right)}
$$

and the measure of the inclusion of the set of features of the $j$-th variant in the $i$-th:

$$
W\left(R_{i} ; R_{j}\right)=\frac{m\left(R_{i} \cap R_{j}\right)}{m\left(R_{j}\right)}
$$

Based on (3) and (4), we calculate the values of the elements of the inclusion measure matrix (Table 2b), in percent, by rounding the obtained values to whole numbers.

The element of the intersection matrix (Table 2c) in the $i$-th row and $j$-th column is $m\left(R_{i} \cap R_{j}\right)$, from here. The elements of the similarity matrix (Table $2 \mathrm{~d}$ ) are calculated by the formula (2).

Example: 
For variants $R_{1}$ and $R_{2}$, the number of types in the descriptions of attributes $m\left(R_{1}\right)=7$, $m\left(R_{2}\right)=7, m\left(R_{1} \cap R_{2}\right)=5$. Then

$$
W\left(R_{2} ; R_{1}\right)=\frac{m\left(R_{1} \cap R_{2}\right)}{m\left(R_{1}\right)}=\frac{5}{7}=71 \%
$$

(second line first column of table 2, b)

$$
W\left(R_{1} ; R_{2}\right)=\frac{m\left(R_{1} \cap R_{2}\right)}{m\left(R_{2}\right)}=\frac{5}{7}=71 \%
$$

(first line second column of table 2, b). Accordingly, in table 2, c, the first line is $m\left(R_{1}\right)=7$, the second line the first column $m\left(R_{1} \cap R_{2}\right)=5$, the second line the second column $\mathrm{m}\left(R_{2}\right)=7$, and in the table $2, \mathrm{~d}$

$$
C\left(R_{1} R_{2}\right)=\frac{2 m\left(R_{1} \cap R_{2}\right)}{m\left(R_{1}\right)+m\left(R_{2}\right)}=\frac{2 \cdot 5}{7+7}=\frac{10}{14}=71 \%
$$

(first line first column of the table 2, d).

As it can be seen from the similarity matrix (table $2, d$ ), the highest value in the column of the prototype $R_{1}$, equal to 92 , is for the line of the prototype $R_{4}$. Consequently, the TM suspension of the diesel locomotive TEM103, which is used as a prototype, is close to the designed object. Further, the substructure is distinguished in the suspension design, which distinguishes it from the prototype of the part, and a prototype substructure is searched for it. Thus, it is possible to automate the process of prompting typical solutions, which solves the problem of searching for elements in catalogs (for example, in [18-20]).

Associated with the prototype in the database is textual and graphical reference information about the experience of mastering production and operation, with a description of the identified deficiencies, problems encountered, research data, etc.

It is known that when using the considered suspension on a three-axle jawless bogie of the $2 \mathrm{TE} 10 \mathrm{~m}$ locomotive there were cases of jamming of the hinge sleeve on the axle with extrusion of the rubber sleeve from the hinge due to a change in the friction coefficient between the sleeve and the axle when the sleeve and axis surfaces are contaminated and corroded by moisture. Thus, the proposed object model makes it possible to predict in advance the possible design flaws and to look for ways in advance to solve them, using algorithmic search methods.

Table 2. Types lists and matrix of measures. a) Types lists

\begin{tabular}{|c|c|c|c|c|c|c|c|}
\hline & $\boldsymbol{R}_{1}$ & $\boldsymbol{R}_{2}$ & $\boldsymbol{R}_{3}$ & $\boldsymbol{R}_{4}$ & $\boldsymbol{R}_{5}$ & $\boldsymbol{R}_{6}$ & $\boldsymbol{R}_{7}$ \\
\hline$S_{1}$ & 1 & 1 & 1 & 1 & 1 & 1 & 0 \\
\hline$S_{2}$ & 0 & 0 & 0 & 0 & 0 & 0 & 1 \\
\hline$S_{3}$ & 1 & 1 & 1 & 1 & 1 & 0 & 0 \\
\hline$S_{4}$ & 1 & 1 & 0 & 0 & 0 & 1 & 1 \\
\hline$S_{5}$ & 0 & 0 & 0 & 1 & 1 & 0 & 0 \\
\hline
\end{tabular}




\begin{tabular}{|l|l|l|l|l|l|l|l|}
\hline$S_{6}$ & 1 & 0 & 1 & 1 & 1 & 0 & 0 \\
\hline$S_{7}$ & 0 & 0 & 0 & 0 & 0 & 1 & 1 \\
\hline$S_{8}$ & 1 & 1 & 1 & 1 & 1 & 1 & 1 \\
\hline$S_{9}$ & 1 & 1 & 1 & 1 & 1 & 1 & 1 \\
\hline$S_{10}$ & 1 & 0 & 1 & 1 & 1 & 1 & 1 \\
\hline$S_{11}$ & 0 & 1 & 0 & 0 & 0 & 0 & 0 \\
\hline$S_{12}$ & 0 & 1 & 0 & 0 & 0 & 0 & 0 \\
\hline
\end{tabular}

b) Inclusion matrix

\begin{tabular}{|l|c|c|c|c|c|c|c|}
\hline & $\boldsymbol{R}_{\boldsymbol{1}}$ & $\boldsymbol{R}_{\boldsymbol{2}}$ & $\boldsymbol{R}_{3}$ & $\boldsymbol{R}_{4}$ & $\boldsymbol{R}_{5}$ & $\boldsymbol{R}_{\boldsymbol{6}}$ & $\boldsymbol{R}_{7}$ \\
\hline$R_{1}$ & & 71 & 100 & 86 & 86 & 83 & 87 \\
\hline$R_{2}$ & 71 & & 67 & 57 & 57 & 67 & 56 \\
\hline$R_{3}$ & 86 & 57 & & 86 & 86 & 87 & 50 \\
\hline$R_{4}$ & 86 & 57 & 100 & & 100 & 67 & 50 \\
\hline$R_{5}$ & 86 & 57 & 100 & 100 & & 67 & 50 \\
\hline$R_{6}$ & 71 & 57 & 67 & 57 & 57 & & 83 \\
\hline$R_{7}$ & 57 & 43 & 50 & 43 & 43 & 83 & \\
\hline
\end{tabular}

c) Intersection matrix

\begin{tabular}{|l|c|c|c|c|c|c|c|}
\hline$R_{1}$ & 7 & - & - & - & - & - & - \\
\hline$R_{2}$ & 5 & 7 & - & - & - & - & - \\
\hline$R_{3}$ & 6 & 4 & 6 & - & - & - & - \\
\hline$R_{4}$ & 6 & 4 & 6 & 7 & - & - & - \\
\hline$R_{5}$ & 6 & 4 & 6 & 7 & 7 & - & - \\
\hline$R_{6}$ & 5 & 4 & 4 & 3 & 4 & 6 & - \\
\hline$R_{7}$ & 4 & 3 & 3 & 3 & 3 & 5 & 6 \\
\hline & $R_{1}$ & $R_{2}$ & $R_{3}$ & $R_{4}$ & $R_{5}$ & $R_{6}$ & $R_{7}$ \\
\hline
\end{tabular}

d) Similarity measure matrix

\begin{tabular}{|l|c|c|c|c|c|c|}
\hline$R_{2}$ & 71 & - & - & - & - & - \\
\hline$R_{3}$ & 92 & 62 & - & - & - & - \\
\hline$R_{4}$ & 86 & 57 & 92 & - & - & - \\
\hline
\end{tabular}




\begin{tabular}{|l|c|c|c|c|c|c|}
\hline$R_{5}$ & 86 & 57 & 92 & 100 & - & - \\
\hline$R_{6}$ & 77 & 62 & 67 & 62 & 62 & - \\
\hline$R_{7}$ & 62 & 46 & 50 & 46 & 46 & 83 \\
\hline & $\boldsymbol{R}_{\boldsymbol{1}}$ & $\boldsymbol{R}_{\mathbf{2}}$ & $\boldsymbol{R}_{3}$ & $\boldsymbol{R}_{5}$ & $\boldsymbol{R}_{\boldsymbol{6}}$ & $\boldsymbol{R}_{7}$ \\
\hline
\end{tabular}

Let us consider an example of solving the above problem. We will proceed from the impossibility to increase the length of the suspension when assembling it in a three-axle bogie, which makes it impossible to provide lateral movements of the TM core due to deformation of the rubber of the hinges and to exclude mixing the bushing of one or both hinges along the axis. Only the variant [21] is known, where the transverse displacement of the TM was partially provided by the skewing of the rubber-metal hinges (silent blocks), and partly due to their transverse movement along the axes. It contains bearing supports for support on the axis of the wheelset and the lead, the ends of the silent blocks connected to the engine case and the truck frame, one of the silent blocks mounted on the axis with the possibility of axial movement within 1-1.2 of the maximum amplitude transverse displacements of the wheelset relative to the frame of the carriage, and the parameters of the silent blocks are connected by the following relationship:

$$
f \leq \frac{1}{\left[\frac{F\left(2 \cdot l^{2} \cdot S_{r}+6 \cdot L^{2} \cdot S_{r}\right)}{S_{a} \cdot l^{2} \cdot S_{r} \cdot \Delta}+\frac{L}{t}\right]}
$$

where $f$ is a coefficient of sliding friction of the suspension on the inner roller; $F$ is the total force in the suspension from the weight of the traction motor and the reactive force from the realization of the thrust force, $\mathrm{kN} ; L$ - center-to-center distance by suspension shock absorbers, $\mathrm{mm}$; $t$ is the length of the internal sleeve of the shock absorber, $\mathrm{mm} ; S_{r}-$ radial stiffness of the shock absorber, $\mathrm{kN} / \mathrm{mm} ; S_{a}$ - axial stiffness of the shock absorber, $\mathrm{kN} / \mathrm{mm} ; \Delta$ is the amplitude of the transverse displacement of the wheelset with the electric motor relative to the frame of the bogie, $\mathrm{mm}$.

Since the friction coefficient $f$ of the sleeve on the axis surface in operation may vary due to thickening of the lubricant, dirt and rust, when the driver skews during operation, the sleeve pressure on the axis surface is uneven due to the moment of resistance of the silent block to skew, which leads to uneven wear sleeve and axle and reduce the actual length of the contact sleeve with the axis compared to the design, and when the temperature changes, the radial and axial stiffness of the shock absorber will change. This can lead to seizure of the suspension.

Let us try to find a solution using the algorithms described in [22]. Since the suspension functions are known, we will decompose only to the level of physical effects and determine the antagonizing properties. The cause of jamming is a suspension of the suspension thrust, leading to an uneven distribution of loads along the length of the sleeve. The distortion of thrust in the known suspension is inevitable, since the lateral displacements are partially compensated for by the suspension of the suspension, and in part by the movement of the hinge sleeves along the axes. Reducing the stiffness of the hinge at the skew reduces the moment of resistance to skew and the uneven distribution of loads along the sleeve, but this reduces the longitudinal force, trying to overcome the friction forces and move the hinge sleeve along the axis. Thus, the antagonism of properties lies in the fact that the rigidity of the hinges on a bias to prevent jamming must be simultaneously reduced and increased. 
Antagonism is resolved by dividing the properties of the hinges. One of the hinges is stationary in the axial direction and non-skewing (rigid to skew), and the second, on the contrary, can be made with the possibility of displacements in the axial direction and has minimal skew resistance, for which the second hinge is spherical. A patent for an invention was obtained for this decision (Fig. 3 a-b) [23].

The lower silentblock 3 is mounted on an axis with the possibility of axial movement, and the upper silentblock 4 has a cylindrical rubber sleeve, the length of which is $t_{B}$ is not less than $2 / 3$ of the center-to-center distance along the hinges of the suspension $L$. (It is known that, in axle-box links, the length of a rubber bushing of a longer link is chosen to be at least $2 / 3$ of the center-to-center distance in order to impart transverse rigidity). The friction force does not cause the link 2 to tilt relative to axis 5, due to the fact that the length $t_{B}$ of the rubber bush of the upper silentblock 4 is at least $2 / 3$ of the center-to-center distance along the hinges of the suspension $L$.

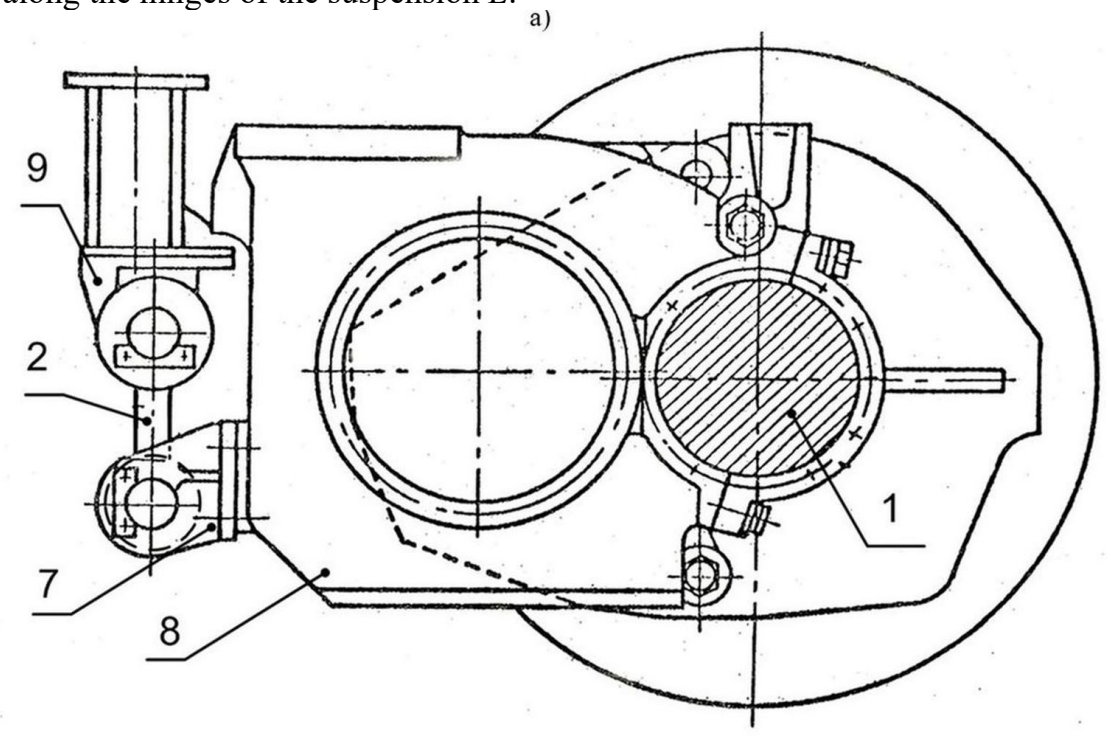

a) 


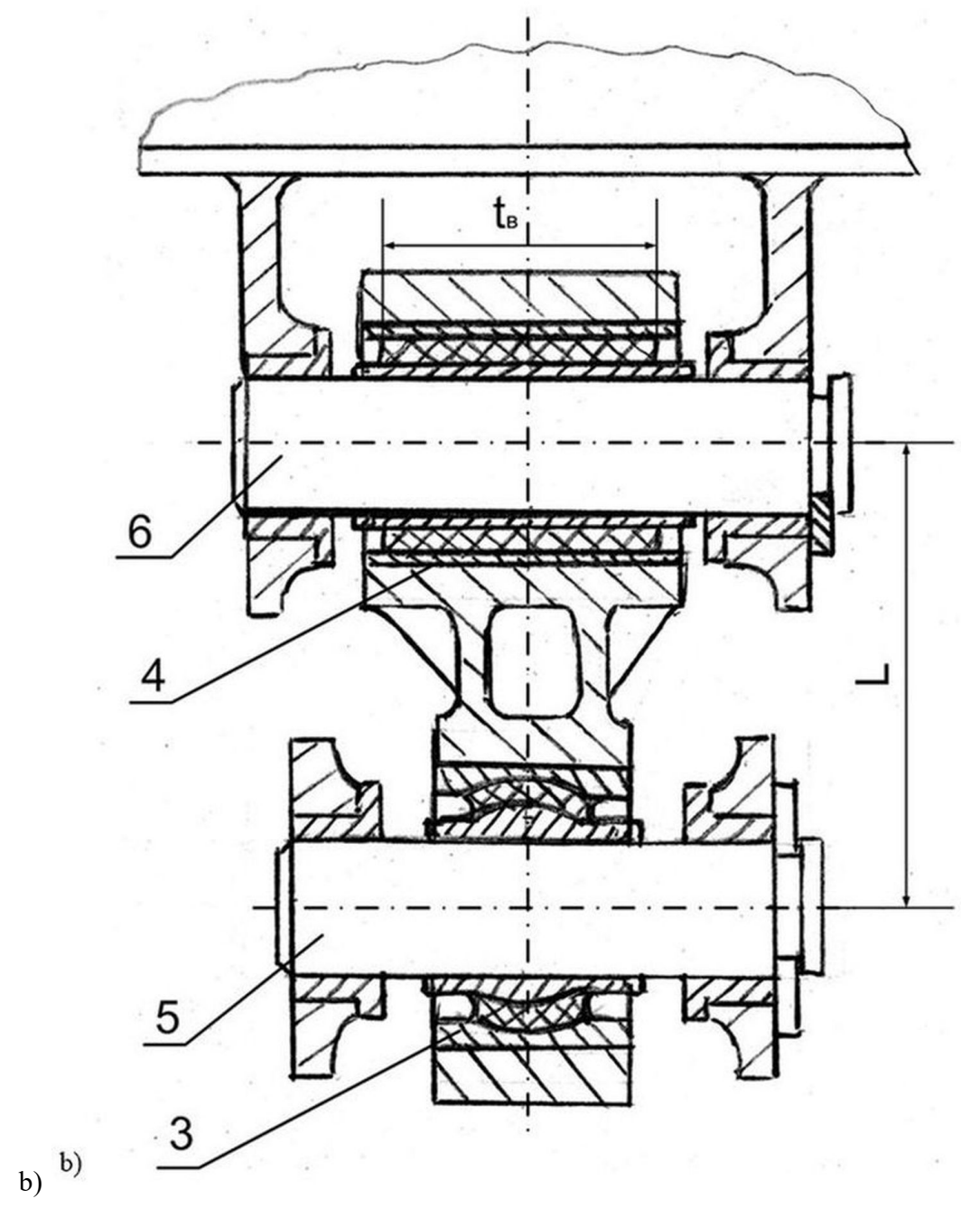




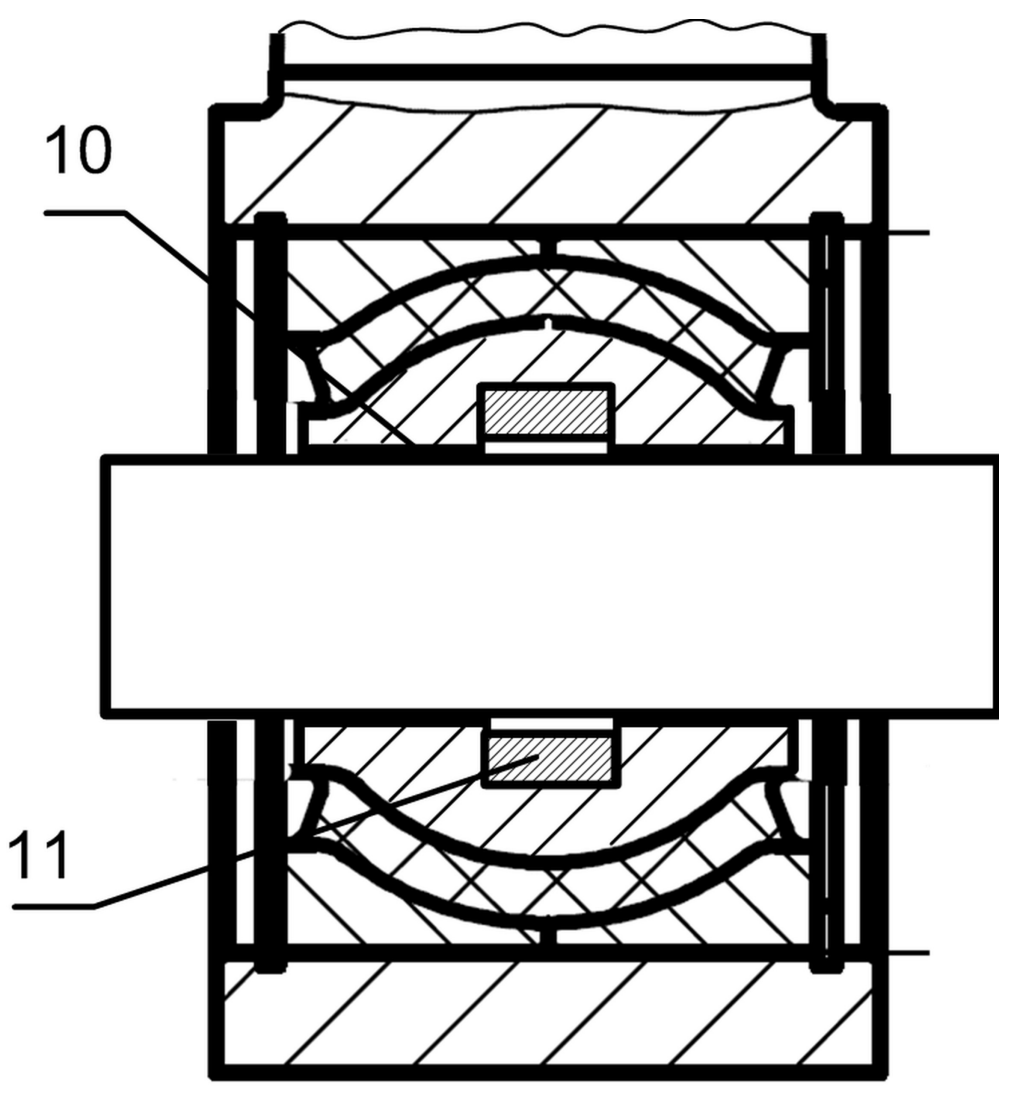

c)

Fig. 3. TM suspension with spherical and cylindrical hinges a - general view, b - suspension type, c lower hinge device. 1 - bearing supports; 2 - a leash; 3,4 - silent blocks; 5,6 - axis; 7- bracket; 8 - TM housing; 9 - bogie frame; 10 - lubricating fluid; 11 - permanent magnets

The absence of skew of the link 2 leads to the absence of skew of the lower silent block 3 , as a result of which the pressure of the inner sleeve of the silent block 3 on the axis 5 spreads evenly along the length of the contact of the silent block 4 and axis 5, which prevents destruction of the layer of lubricant 10 and jamming of the silent block 4 on axis 5 . Due to the fact that the rubber bush of the silent block 3 has a spherical shape, the nonparallelism of the axles 5 and 6 of the silent blocks 3 and 4, resulting from the unequal height of the irregularities of the right and left rails of the track, also does not cause uneven pressure distribution of the inner casing of the silent block 3 on the axis 5 along the length of the contact of the silent block 4 and axis 5. The permanent magnets 11 hold the lubricant in the gap between the silent block 3 and axis 5, preventing the occurrence of dry friction and scuffing of the contacting surfaces of the axis and the silent block. A variant with two cylindrical sleeves in the upper silent block has also been patented [24].

For the implementation of the proposed suspension, it is necessary to cut the nozzles of the traction motor, which makes it impossible to further use the TM in locomotives that have not yet been upgraded. The authors proposed a design variant in which the upper hinge is placed between the nozzles, and instead of the lower cylindrical hinge, two spherical ones are used, located on both sides of the TM lower nozzle. The design is patented [25]. 


\section{Conclusions}

1. The question of choosing a mathematical model for the design of a locomotive drive is considered. It has been established that the main drawback of the known methods of modeling new technical solutions for the mechanical part of a locomotive drive is the use of an elemental-evolutionary approach.

2. An object model for the design of a locomotive train drive is proposed in the form of a hierarchy of description sets with varying degrees of its schematization and a library of typical object descriptions in the form of a hierarchical structure of functional interaction between elements (I-graph), which makes it possible to implement automatic prompts in the form of standard constructions from the description library found using matrices of similarity measures. The proposed design model reduces the number of design errors due to the fact that the new design is implemented with the maximum use of previously studied and technologically mature counterparts.

3. The application of the proposed object model allowed us obtain new patentable solutions for traction drive suspension. A patent for the invention and two patents for utility models are obtained.

\section{References}

1. J. Liu, S. Li and M. Krishnamurthy, Transportation Electrification Conference and Expo (ITEC), (2013)

2. L. M. Szklarski Underground Electric Haulage Elsevier, 420 (2013)

3. G. Popa and S. Arsene, International Conference on Electrical Systems for Aircraft, Railway and Ship Propulsion, ESARS, 5665213, (2010)

4. Yu. N. Pavlovsky, Fundamentals of mathematical modeling for complex systems, 1, 14 (2001)

5. S. Duda, Journal of theoretical and applied mechanics, 52:2, 395 (2014)

6. Ertas, and J. C. Jones, The Engineering Design Process (John Wiley and Sons, New York, 1996)

7. E. Lumsdaine, M. Lumsdaine, and J. W. Shelnutt, Creative Problem Solving and Engineering Design, (McGraw-Hill, Inc., New York, 1999)

8. M. S. Sanders and E. J. McCormick, Human Factors in Engineering and Design, (McGraw-Hill, Inc., New York, 1993)

9. L. Dym and P. Little, Engineering Design: A Project-Based Introduction, John Wiley, New York, 1999

10. Hyman, Fundamental of Engineering Design, Prentice Hall, New Jersey, 1998.

11. R. G. Budynas and J. K. Nisbett, Shigley's mechanical engineering design, (McGrawHill Education, 2015)

12. Simon, A. Bataller, J. Cabrera, F. Ezquerro, A. J. Guerra, F. Nadal and A. Ortiz, Fundamentals of Machine Theory and Mechanisms, (Springer, 2016)

13. R. C. Juvinall and K. M. Marshek, Fundamentals of Machine Component Design (John Wiley \& Sons, Inc., 2006)

14. R. L. Norton, Design of Machinery: An Introduction to the Synthesis and Analysis of Mechanisms and Machines, (Mcgraw-Hill College, 2005)

15. Railway technical handbook, SKF Group, 2, 236 (2012)

16. E. Gorodetskiy and I. L. Tarasova, Smart Electromechanical Systems, (Springer, 2019)

17. G. Booch, R. Maksimchuk, M. Engle, J. Conallen, K. Houston and B. Young, ObjectOriented Analysis and Design with Applications, (Addison Wesley, 2007)

18. R. Koller, Konstructions methode fur den Mashinen-, Gerate- und Apparatebau, (Springer, Verlag, 1976) 
19. K. Roth, Konstruieren mit Konstruktionskatalogen. Band 1: Konstruktionslehre, (Springer, Berlin, 2000)

20. Ya. Antipin, IOP Conf. Series: Materials Science and Engineering, 450 (2018)

21. L. P. Lingaitis, S. Lebedevas and L. Liudvinavičius, Eksploatacja i Niezawodnosc Maintenance and Reliability, 16:1, 73 (2014)

22. V. I. Vorobiev, O. V. Dorofeev, O. V. Izmerov, M.I. Borzenkov, A.S. Kosmodamianskij, S.I. Zlobin, A.A. Pugachev, S.O. Kopylov and V.O. Korchagin, Synthesis of new solutions for transport system drives in intelligent CAD system, (Orel State University named after I.S. Turgenev, 2017)

23. A.A. Pugachev, S. G. Volohov, O. V. Izmerov, V. I. Vorobiev, G. S. Mihalchenko and V. G. Novikov, Patent No. 2549427 Suspension unit for traction motor, (2015)

24. V. G. Novikov, V. I. Vorobiev, O. V. Izmerov and V. P. Tihomirov, Patent for utility model No. 176428 Suspension unit for traction motor, (2018)

25. Ya. Antipin, V. I. Vorobiev, O. V. Izmerov, S. O. Kopylov, M. A. Maslov and S. G. Shorohov, Patent for utility model No. 176843 Suspension unit for traction motor (2018) 